\title{
BAP1 (BRCA1-associated protein 1) is a highly specific marker for differentiating mesothelioma from reactive mesothelial proliferations
}

Marta Cigognetti ${ }^{1}$, Silvia Lonardi ${ }^{1}$, Simona Fisogni ${ }^{1}$, Piera Balzarini ${ }^{1}$, Vilma Pellegrini $^{1}$, Andrea Tironi ${ }^{1}$, Luisa Bercich ${ }^{1}$, Mattia Bugatti ${ }^{1}$, Giulio Rossi ${ }^{2}$, Bruno Murer ${ }^{3}$, Mattia Barbareschi ${ }^{4}$, Silvia Giuliani ${ }^{4}$, Alberto Cavazza ${ }^{5}$, Gianpietro Marchetti ${ }^{6}$, William Vermi $^{1}$ and Fabio Facchetti ${ }^{1}$

${ }^{1}$ Department of Molecular and Translational Medicine, Section of Pathology, University of Brescia, Spedali Civili, Brescia, Italy; ${ }^{2}$ Department of Pathology, Azienda Ospedaliero-Universitaria Policlinico of Modena, Modena, Italy; ${ }^{3}$ Department of Pathology, Ospedale Dell'Angelo, Venezia-Mestre, Italy; ${ }^{4}$ Unit of Surgical Pathology, S. Chiara Hospital, Trento Italy; ${ }^{5}$ Department of Pathology, Azienda Arcispedale S. Maria Nuova IRCCS, Reggio Emilia, Italy and ${ }^{6}$ Department of Pneumology, Spedali Civili, Brescia, Italy

The distinction between malignant mesothelioma and reactive mesothelial proliferation can be challenging both on histology and cytology. Recently, variants of the BRCA1-associated protein 1 (BAP1) gene resulting in nuclear protein loss were reported in hereditary and sporadic mesothelioma. Using immunohistochemistry, we evaluated the utility of BAP1 expression in the differential diagnosis between mesothelioma and other mesothelial proliferations on a large series of biopsies that included 212 mesotheliomas, 12 benign mesothelial tumors, and 42 reactive mesothelial proliferations. BAP1 stain was also performed in 70 cytological samples (45 mesotheliomas and 25 reactive mesothelial proliferations). BAP1 was expressed in all benign mesothelial tumors, whereas 139/212 (66\%) mesotheliomas were BAP1 negative, especially in epithelioid/biphasic compared with sarcomatoid/desmoplastic subtypes (69\% vs $15 \%$ ). BAP1 loss was homogeneous in neoplastic cells except for two epithelioid mesotheliomas showing tumor heterogeneity. By fluorescence in situ hybridization, BAP1 protein loss was paralleled by homozygous deletion of the BAP1 locus in the vast majority of BAP1-negative tumors $(31 / 41,76 \%)$, whereas 9/10 BAP1-positive mesotheliomas were normal. In biopsies interpreted as reactive mesothelial proliferation BAP1 loss was $100 \%$ predictive of malignancy, as all 6 cases subsequently developed BAP1-negative mesothelioma, whereas only $3 / 36(8 \%)$ BAP1-positive cases progressed to mesothelioma. On cytology/cell blocks, benign mesothelial cells were invariably positive for BAP1, whereas $64 \%$ of mesotheliomas showed loss of protein; all 6 cases showing BAP1 negativity were associated with histological diagnosis of BAP1-negative mesothelioma. BAP1 stain also showed utility in the differential of mesothelioma from most common pleural and peritoneal mimickers, such as lung and ovary carcinomas, with specificity and sensitivity of $99 / 70 \%$ and $100 / 70 \%$, respectively. Our results show that BAP1 protein is frequently lost in mesothelioma, especially of epithelioid/biphasic subtype and is commonly associated with homozygous BAP1 deletion. BAP1 immunostain represents an excellent biomarker with an unprecedented specificity $(100 \%)$ in the distinction between benign and malignant mesothelial proliferations. Finding BAP1 loss in mesothelial cells should prompt to immediately reevaluate the patient; moreover, it might be useful in mapping tumor extent and planning surgical resection.

Modern Pathology (2015) 28, 1043-1057; doi:10.1038/modpathol.2015.65; published online 29 May 2015

Correspondence: Professor F Facchetti, MD, PhD, Department of Molecular and Translational Medicine, Section of Pathology, University of Brescia, Spedali Civili, Brescia 25123, Italy.

E-mail: fabio.facchetti@unibs.it

Received 14 February 2015; revised 20 April 2015; accepted 24 April 2015; published online 29 May 2015
The diagnosis of malignant mesothelioma and its distinction from serosal involvement by other malignant processes and from benign mesothelial proliferations is of primary importance not only to patient treatment and prognosis, but also for its forensic 
implications, because of the occupational nature of mesothelioma. In the United States, after a peak registered in 2000-2004, malignant mesothelioma incidence decreased,,$^{1,2}$ with a rate between 2007 and 2011 of 1.9 and 0.4 per 100000 inhabitants, respectively, in men and women. ${ }^{3}$ Higher incidence has been observed in Italy where between 1993 and 2008, the National Mesothelioma Registry recorded 3.55 (male) and 1.35 (female) cases of malignant mesothelioma per 100000 inhabitants. ${ }^{4,5}$ Moreover, either the late asbestos ban or the long latency period for full transformation to mesothelioma validate the expected increasing incidence trend and peak within 10-15 years in Italy, as well as in other European countries. ${ }^{4,6,7}$

Immunohistochemistry is of definite support to the differential diagnosis between mesothelioma and serosal involvement by extraserosal neoplasms, $, 8,9$ and although the distinction of mesothelioma from reactive mesothelial proliferations remains challenging, it is fundamentally based on the demonstration of stromal invasion, ${ }^{10-12}$ with limited support by immunohistochemistry. ${ }^{12}$ In fact, a variety of markers, such as desmin, epithelial membrane antigen, p53, IMP3, GLUT-1, CD146, and CD147, have been evaluated on both tissue and cytological samples, but none of them appeared to achieve sufficient diagnostic adequacy in the separation between malignant and benign mesothelial lesions. ${ }^{13-36}$

Using fluorescence in situ hybridization (FISH), the homozygous deletion of $C D K N 2 A$ gene is found in $52-88 \%$ of mesotheliomas, but not in reactive mesothelial proliferations; ${ }^{23,37-39}$ using a cut-off value of $10 \%$ positive mesothelial cells, p16 protein expression resulted to be closely related to $C D K N 2 \mathrm{~A}$ status in some, ${ }^{23,38}$ but not all, studies, ${ }^{37}$ thus hampering its use as a reliable marker to distinguish mesothelioma from reactive mesothelial proliferations.

Recently, Carbone et al ${ }^{40}$ identified a novel cancer syndrome related to germline BRCA1-associated protein 1 (BAP1) loss-of-function mutations and inherited with dominant autosomal transmission. Family members bearing $B A P 1$ germline mutations show increased susceptibility to develop a variety of neoplasms, including uveal melanoma, cutaneous melanoma, atypical Spitz tumor, clear cell renal cancer, basal cell carcinoma, and mesothelioma, the latter occurring independently from occupational or environmental asbestos exposure. ${ }^{40}$

Initially identified as a BRCA1-binding protein, BAP1 is a deubiquitinating enzyme with C-terminal active hydrolase domain (UCH) and N-terminal nuclear localization signals (NLS1, NLS2). ${ }^{41,42}$ Its tumor suppressor functions have been recently described and it has been found that BAP1 plays a role in cycle-cell progression, DNA ionizing radiation breaks repair, gene expression regulation through hystone $\mathrm{H} 2 \mathrm{~A}$ deubiquitinase activity, and subsequent chromatin remodeling. ${ }^{42-49}$ As further evidence of $B A P 1$ as a tumor suppressor gene, somatic gene inactivating deletions or point mutations have been detected in the same types of neoplasms associated with $B A P 1$-cancer syndrome. ${ }^{50-53}$ Bott et $a l^{54}$ first reported $B A P 1$ somatic variants in malignant mesothelioma, identifying gene losses and/or mutations in 22 of 53 pleural mesotheliomas $(42 \%)$ that resulted in absent BAP1 immunoreactivity in tumor cells; interestingly, immunohistochemical analysis revealed a negative BAP1 staining also in eight cases in which mutations were not detected. ${ }^{54}$ Yoshikawa et $a l^{55}$ observed frequent deletion of the 3 p21.1 region in mesothelioma primary cultures and cell lines; the same authors subsequently detected somatic biallelic $B A P 1$ alterations in 14 of 23 cases of mesothelioma (61\%); ${ }^{56}$ similar percentages of cases showing loss of BAP1 protein expression were found in other more recent studies. ${ }^{57,58}$

In a recent study performed on tissue microarray containing 49 benign and 26 malignant mesothelial proliferations, Sheffield et $a l^{39}$ showed that BAP1 immunostain separates benign from malignant processes, with a $100 \%$ specificity and $27 \%$ sensitivity; sensitivity increased to $58 \%$ when BAP1 stain was combined with 9p21 FISH analysis. In their study, a roughly equivalent number of epitheloid/biphasic and sarcomatoid mesothelioma cases were included, but whether BAP1 reactivity differed between subtypes was not specified.

In this study, we evaluated the diagnostic utility of BAP1 expression using a large series of histological samples, including 12 benign mesothelial tumors, 42 simple or atypical reactive mesothelial proliferations, and 212 mesotheliomas. The results fully supported the diagnostic role of anti-BAP1 as biomarker to distinguish benign from malignant mesothelial proliferations; specificity and sensitivity reached $100 \%$ and $66 \%$, respectively, the latter raising to $69 \%$ when only epithelioid/biphasic subtypes were included. FISH analysis of $B A P 1$ gene demonstrated that homozygous deletion of the $B A P 1$ locus was commonly associated with BAP1 protein loss. Finally, the utility of BAP1 immunohistochemistry was also proven on cytological and cellblock samples.

\section{Materials and methods}

\section{Case Selection}

Histological, cytological, and cell-block samples were collected from the pathology archives from University-Spedali Civili of Brescia, Policlinico Hospital (Modena), IRRCCS (Reggio Emilia), Angelo Hospital (Mestre), and S. Chiara Hospital (Trento). All cases had been diagnosed or reviewed by pathologists with expertise in pleuropulmonary pathology.

Histological diagnoses of cases included in the study are reported in Table 1. Normal mesothelium, covering lung tissue (4 cases) or tuba (7 cases) from 
Table 1 BAP1 immunoreactivity in tissues biopsies

\begin{tabular}{lcc}
\hline Diagnosis & No. of cases & BAP1 loss (\%) \\
\hline Normal mesothelium & 11 & $0 / 11(0)$ \\
Benign mesothelial tumor & 12 & $0 / 12(0)$ \\
Benign multicystic mesothelioma & 3 & $0 / 3$ \\
Benign papillary mesothelioma & 2 & $0 / 2$ \\
Adenomatoid tumor & 7 & $0 / 7$ \\
Malignant mesothelioma & 212 & $139 / 212(66)$ \\
Epithelioid & 184 & $128 / 184(70)$ \\
Biphasic & 15 & $9 / 15(60)$ \\
Sarcomatoid & 8 & $1 / 8(13)$ \\
Desmoplastic & 5 & $1 / 5(20)$ \\
Reactive mesothelial proliferation & 42 & $6 / 42(14)$ \\
Simple & 27 & $2 / 27(7)^{\mathrm{a}}$ \\
Atypical & 15 & $4 / 15(27)^{\mathrm{a}}$ \\
\hline
\end{tabular}

aAll BAP1-negative cases developed malignant mesothelioma.

samples surgically removed for nonmesothelialrelated diseases, was used as control. Benign mesothelial tumors included three abdominal benign multicystic mesotheliomas, two abdominal benign papillary mesotheliomas, three uterine, and four paratesticular adenomatoid tumors. A total of 212 biopsies of mesothelioma obtained from the same number of patients included either thoracoscopic biopsies (136 cases) or surgical specimens (76 cases) and had been removed from pleura (207 cases) or peritoneum (5 cases); in all cases, diagnosis was based on clinical and imaging data, and fully supported by both positive and negative mesothelioma immunohistochemical markers, as recommended. ${ }^{8,9}$ A total of 42 biopsies classified as reactive mesothelial proliferation were obtained from 41 patients and were further subclassified as simple reactive mesothelial proliferation (27 cases) or atypical reactive mesothelial proliferation (15 cases), according to Churg et al. ${ }^{10}$ These samples (40 thoracoscopic biopsies and 2 surgical specimens) were removed from pleura (38 cases) or peritoneum (4 cases); 28 pleural biopsies were performed in symptomatic patients with recurrent effusion/pleuritis and past asbestos exposure (15 cases) and/or thoracoscopic anomalies (13 cases). Clinical data from cases of reactive mesothelial proliferation are reported in Table 2 . In addition, five surgical tissue blocks were part of an extensive sampling of invasive pleural mesothelioma and were classified as atypical reactive mesothelial proliferation because of absence of stromal invasion.

Cytological and cell-block samples included 18 cases of benign mesothelial reaction associated with inflammation (15 cases) or lung adenocarcinoma (2 cases), 45 cases of mesothelioma, and 8 samples defined as atypical mesothelial cells of indeterminate nature. Data on cytological/cell-block samples are reported in Table 3.

A large series of nonmesothelial pleural and peritoneal malignant tumors most commonly included in the differential diagnosis with mesothelioma were also enrolled in the study; they were represented by 184 cases of lung adenocarcinoma (all major subtypes), 21 cases of lung squamous cell carcinoma, 95 cases of ovarian carcinoma (all major subtypes), and 8 cases of lung epithelioid hemangioendothelioma. Lung and ovarian tumors were tissue microarrays samples (containing from two to four representative $1 \mathrm{~mm}$ cores for each case), whereas epithelioid hemangioendothelioma were surgical samples (Table 4).

In all cases with histological or cytological diagnosis of reactive mesothelial proliferation, the clinical, radiological, and eventual subsequent histological data were collected during a follow-up period of variable duration (up to 9 years), until pleural disease resolution, frank mesothelioma diagnosis, extramesothelial diseases, or neoplastic nonmesothelial malignancy were identified. Furthermore, the Brescia Province as well as the National Mesothelioma Registries were consulted.

The study was performed in accordance with the institutional ethical board protocols of Brescia, Modena, Reggio Emilia, Mestre, and Trento hospitals.

\section{BAP1 Immunohistochemistry}

On 4- $\mu$ m-thick formalin-fixed, paraffin embedded sections, BAP1 immunostain was performed upon microwave oven epitope retrieval in Tris ethylenediamine tetra-acetic acid (EDTA) buffer ( $\mathrm{pH} 9.0$ ). Sections were incubated for $60 \mathrm{~min}$ with anti-BAP1 mouse monoclonal antibody (clone C-4, Santa Cruz Biotechnology, Santa Cruz, CA, USA) followed by horseradish peroxidase-conjugated Novolink polymer (Leica Microsystem, Newcastle upon Tyne, UK). The reaction was developed using diaminobenzidine (DAB) as chromogen and sections were counterstained with hematoxylin. The same procedure was used for cytological and cell-block samples; the former were represented by slides previously stained with papanicolaou or hematoxylin-eosin, as previously described. ${ }^{59}$

On selected cases, especially to distinguish between mesothelial cells and associated histiocytes, double immunohistochemistry for BAP1 combined either with epithelial membrane antigen (Leica Microsystem), calretinin (Invitrogen, Carlsbad, CA, USA), or cytokeratin 5/6 (Invitrogen) as mesothelial markers and CD11c (Leica Microsystems) and CD68 (clone PGM1, Dako, Glostrup, Denmark) as histiocyte markers was performed, as previously described, ${ }^{60}$ using the Mach 4-alkaline phosphatase (AP) detection system (Biocare Medical, Concord, CA, USA) and Ferangi Blue (Biocare Medical) or New Fucsin (Dako) as chromogens.

Only the nuclear expression of BAP1 was considered for evaluation, despite the fact that in some cases fine granular cytoplasmic positivity was also noticed. All cases contained positive controls represented by nonmesothelial BAP1-reactive cells, such 
Table 2 Clinical features, BAP1 expression, and follow-up of cases of reactive mesothelial proliferation

\begin{tabular}{|c|c|c|c|c|c|}
\hline No. & $\begin{array}{l}\text { Age/ } \\
\text { gender }\end{array}$ & $\begin{array}{l}\text { Histological diagnosis (reactive } \\
\text { mesothelial proliferation) }\end{array}$ & Clinical information and associated lesions/diseases & $B A P 1$ & Follow-up ${ }^{a}$ \\
\hline 1 & $80 / \mathrm{M}$ & Simple & $\begin{array}{l}\text { Serofibrinous pleuritis and lung nodules. Ureter-bladder-urethra carcinoma } \\
5 \text { years later }\end{array}$ & + & Regression (9 years) \\
\hline 2 & $75 / \mathrm{M}$ & Simple & Recurrent pleural effusions & + & NED (9 years) \\
\hline 3 & $58 / \mathrm{M}$ & Simple & $\begin{array}{l}\text { Pleural effusion and inflammatory features on TSP. Sigmoid colon } \\
\text { adenocarcinoma with liver and lung metastases }\end{array}$ & + & Regression (1 year) \\
\hline 4 & $74 / \mathrm{M}$ & Simple & Recurrent pleural effusions & + & Regression (2 years) \\
\hline 5 & $57 / \mathrm{M}$ & Simple & $\begin{array}{l}\text { Pleural effusion; hyperemia and pleural thickening on TSP. Small-cell lung } \\
\text { carcinoma }\end{array}$ & + & Regression (1 year) \\
\hline 6 & $44 / \mathrm{M}$ & Simple & Chronic pleural empyema. Recent pleuropneumonia HIV+ and HCV+ patient & + & Regression (4 years) \\
\hline 7 & $71 / \mathrm{M}$ & Simple & Chronic pleuritis & + & Regression $(<1$ year $)$ \\
\hline 8 & $71 / \mathrm{M}$ & Simple & $\begin{array}{l}\text { Pleural effusion and pulmonary opacity. Previous sigmoid colon } \\
\text { adenocarcinoma with node metastases and high-grade prostatic } \\
\text { intraepithelial neoplasia }\end{array}$ & + & Regression $(<1$ year $)$ \\
\hline 9 & $66 / \mathrm{F}$ & Simple & $\begin{array}{l}\text { Pleural effusion, lung nodule, hilar, and mediastinal lymphadenopathy } \\
\text { Previous breast carcinoma and small-cell lung carcinoma }\end{array}$ & + & Died of small-cell lung cancer (1 year) \\
\hline 10 & $66 / \mathrm{M}$ & Simple & $\begin{array}{l}\text { Pleuritis of unknown origin. Prostate adenocarcinoma and non-Hodgkin’s } \\
\text { B-cell lymphoma of mediastinum }\end{array}$ & + & Regression ( $<1$ year) \\
\hline 11 & $25 / \mathrm{M}$ & Simple & Intraperitoneal ALK+ inflammatory myofibroblastic pseudotumor & + & $\begin{array}{l}\text { Surgery treatment with Crizotinib } \\
\text { NED ( } 20 \text { months) }\end{array}$ \\
\hline 12 & $72 / \mathrm{M}$ & Simple & Lepidic lung adenocarcinoma & + & Regression (1 year) \\
\hline 13 & $61 / \mathrm{F}$ & Simple & Pleural plaques in probable asbestos exposure & + & Regression (1 year) \\
\hline 14 & $68 / \mathrm{F}$ & Simple & $\begin{array}{l}\text { Recurrent pleural effusion; pleural nodules and thickening on TSP; pleural } \\
\text { localization of diffuse large B-cell lymphoma (DLBCL); previous diagnosis of } \\
\text { nodal DLBCL and adenocarcinoma of the endometrium }\end{array}$ & + & NED (30 months) \\
\hline 15 & $75 / \mathrm{M}$ & Simple & Ascites and pleural effusion. Diffuse lymphoid hyperplasia of the omentum & + & NED $(<1$ year $)$ \\
\hline 16 & $23 / \mathrm{F}$ & Simple & Uterine leiomyoma, pelvic endometriosis & + & NED $(<1$ year $)$ \\
\hline 17 & $77 / \mathrm{M}$ & Simple & Plaque-like masses in parietal pleura; classical Hodgkin's lymphoma & + & $\begin{array}{l}\text { Epithelioid BAP1+ mesothelioma } \\
\text { (3 weeks) }\end{array}$ \\
\hline 18 & $78 / \mathrm{F}$ & Simple & Pleural effusion and plaque-like masses and thickening on TSP & - & $\begin{array}{l}\text { Epithelioid BAP1 - mesothelioma } \\
\text { ( } 2 \text { weeks) }\end{array}$ \\
\hline 19 & $76 / F$ & Simple & Pleural effusion and aspecific inflammatory features on TSP & - & $\begin{array}{l}\text { Epithelioid BAP1 - mesothelioma } \\
\text { (26 months) }\end{array}$ \\
\hline 20 & $68 / \mathrm{M}$ & Simple & Cardiac tamponade & + & Regression (1 year) \\
\hline 21 & $56 / \mathrm{M}$ & Simple & Pleuritis & + & Regression $(<1$ year $)$ \\
\hline 22 & $72 / \mathrm{M}$ & Simple & Pleural metastasis from lung adenocarcinoma & + & $\mathrm{NA}$ \\
\hline 23 & $69 / \mathrm{M}$ & Simple & Pleural metastasis from thyroid papillary carcinoma & + & NA \\
\hline 24 & $77 / \mathrm{M}$ & Simple & Pleural metastasis from renal clear cell carcinoma & + & NA \\
\hline 25 & $71 / \mathrm{M}$ & Simple & Pleural metastasis from lung squamous cell carcinoma & + & NA \\
\hline 26 & $72 / \mathrm{M}$ & Simple & Pleural metastasis from lung adenocarcinoma & + & NA \\
\hline 27 & $83 / \mathrm{M}$ & Simple & Pleural fibrin deposition and pleural hyperemia on TSP & + & $\begin{array}{l}\text { Acute pleuritis in Legionella } \\
\text { pneumonia infection }\end{array}$ \\
\hline 28 & $47 / \mathrm{M}$ & Atypical & Pneumothorax and emphysematous bulla & + & NED (8 years) \\
\hline 29 & $59 / \mathrm{M}$ & Atypical & Recurrent pleuritis & + & NED (7 years) \\
\hline 30 & $81 / \mathrm{M}$ & Atypical & $\begin{array}{l}\text { Recurrent pleural effusions and previous diagnosis of nonspecific chronic } \\
\text { pleuritis treated with talc pleurodesis }\end{array}$ & + & Regression (4 years) \\
\hline 31 & $60 / \mathrm{M}$ & Atypical & Pleural effusion; hyperemia and pleural thickening on TSP & + & Regression (2 years) \\
\hline 32 & $78 / \mathrm{M}$ & Atypical & Hemorrhagic pleuritis and hemothorax & + & Regression $(<1$ year $)$ \\
\hline 33 & $81 / \mathrm{M}$ & Atypical & Pleuritis & + & Regression ( $<1$ year) \\
\hline 34 & $53 / \mathrm{M}$ & Atypical & Pleural effusion and nodules of unknown origin & + & Regression ( $<1$ year) \\
\hline
\end{tabular}


Table 3 BAP1 immunoreactivity in cytological and cell-block samples

\begin{tabular}{lcc}
\hline Diagnosis & $\begin{array}{c}\text { No. of } \\
\text { cases }\end{array}$ & $\begin{array}{c}\text { BAP1 loss } \\
(\%)\end{array}$ \\
\hline Benign mesothelial reaction & 17 & $0 / 17(0)$ \\
$\quad$ Inflammatory & 15 & $0 / 15(0)$ \\
$\quad$ Lung adenocarcinoma & 2 & $0 / 2(0)$ \\
Malignant mesothelioma & 45 & $29 / 45(64)$ \\
Atypical mesothelial cells of & 8 & $6 / 8^{\mathrm{a}}(75)$ \\
indeterminate origin & & \\
\hline
\end{tabular}

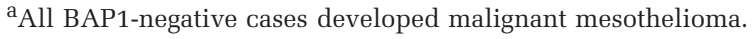

Table 4 BAP1 immunoreactivity in lung and ovary carcinomas and in epithelioid hemangioendothelioma of the lung

\begin{tabular}{lrrr}
\hline & & & \\
& & & \\
\cline { 3 - 4 } & No. of & & \\
cases & Positive & Negative \\
Diagnosis & & & \\
\hline Lung & 184 & $182^{\mathrm{a}}$ & 2 \\
Adenocarcinoma & 111 & 110 & 1 \\
$\quad$ Acinar/acinar+lepidic & 14 & 13 & 1 \\
$\quad$ Solid & 22 & 22 & 0 \\
Solid+lepidic or acinar & 19 & 19 & 0 \\
$\quad$ Lepidic & 9 & 9 & 0 \\
$\quad$ Mucinous & 7 & 7 & 0 \\
Micropapillary & 2 & 2 & 0 \\
Papillary & 21 & 21 & 0 \\
Squamous cell carcinoma & 8 & 8 & 0 \\
Epithelioid & & & \\
hemangioendothelioma & & & \\
Ovary & 71 & $71^{\mathrm{a}}$ & 0 \\
Serous carcinoma & 11 & 11 & 0 \\
Endometrioid carcinoma & 4 & 4 & 0 \\
Undifferentiated carcinoma & 6 & $6^{\mathrm{a}}$ & 0 \\
Clear cell carcinoma & 3 & 3 & 0 \\
Mucinous carcinoma & & & \\
\hline
\end{tabular}

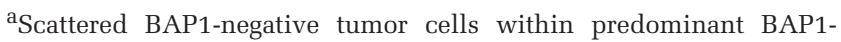
positive tumor cells were identified in one or two cores from 18 cases of lung adenocarcinoma (13), serous (4), and clear cell (1) ovarian carcinoma, respectively.

as inflammatory cells, fibroblasts, pneumocytes, or endothelial cells (Figure 1). On occasional cases, nuclei of neutrophils or lymphocytes were weakly positive or negative for BAP1. The 'positivity' or 'negativity' of mesothelial cells was defined as unambiguous presence or absence of BAP1 expression in mesothelial nuclei, without percentage or intensity cutoff values.

\section{FISH for BAP1}

FISH analysis for BAP1 gene anomalies was performed on 51 mesothelioma biopsies, 41 showing BAP1 protein loss, 10 with normally expressed protein, as well as on 6 control samples with nontumoral mesothelium. 

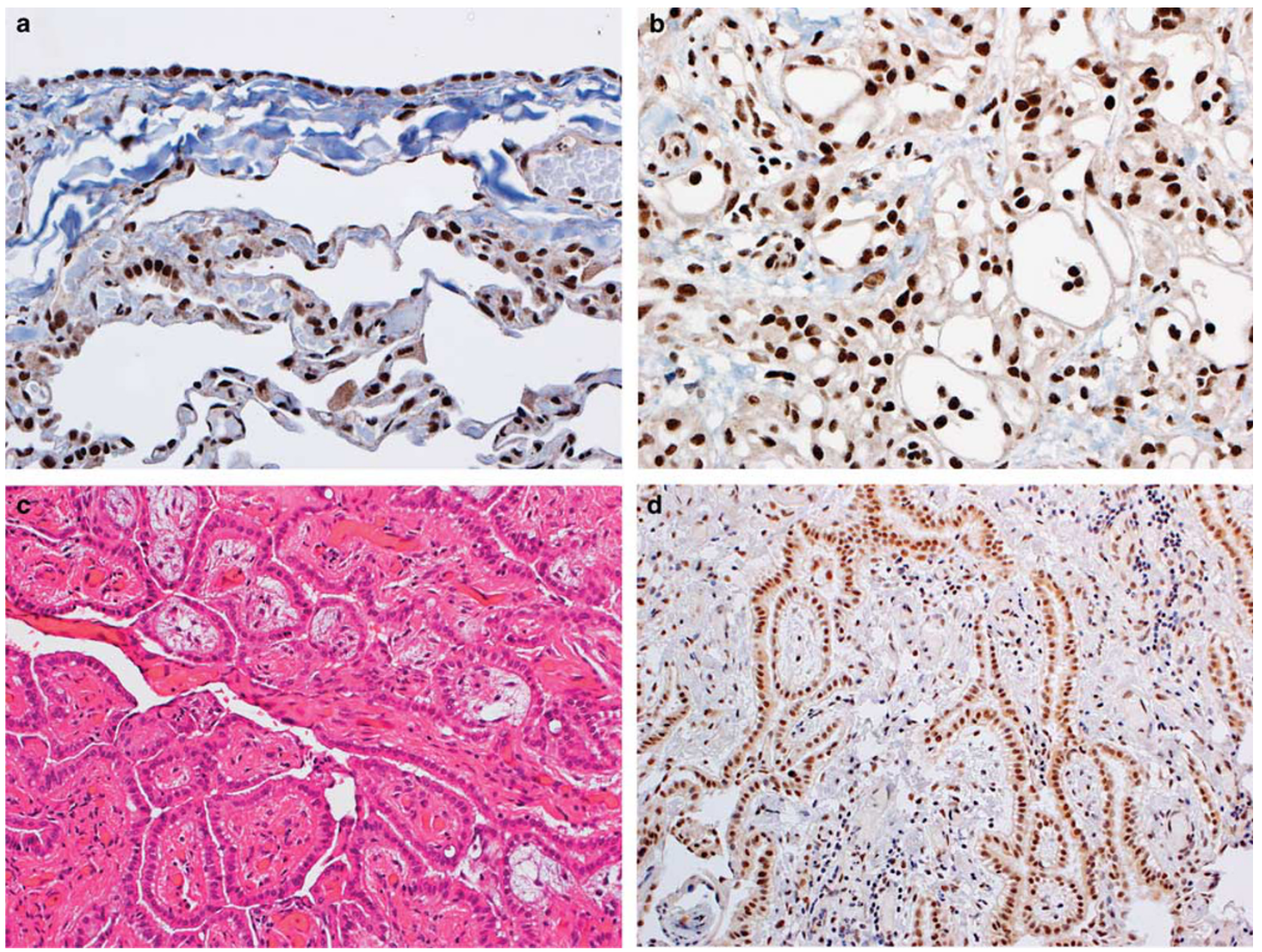

Figure 1 Positive BAP1 immunoreactivity in normal mesothelium and lung alveolar epithelium (a) and in a case of adenomatoid tumor (b); in a peritoneal benign papillary mesothelioma (c, hematoxylin and eosin), BAP1 is also strongly expressed by mesothelial cells (d).

Deparaffinized tissue sections were treated with $\mathrm{HCl}$ $0.2 \mathrm{~N}$ for $20 \mathrm{~min}$, subsequently with the pretreatment solution (Vysis Paraffin Pretreatment Kit; Abbott Molecular, Des Plaines, IL, USA) at $82^{\circ} \mathrm{C}$ for $30 \mathrm{~min}$ and digested with protease I, $250 \mathrm{mg}$ at $37^{\circ} \mathrm{C}$ for $10 \mathrm{~min}$. Samples were incubated with the $B A P 1 / C E N 3 q$ probe (Abnova, Taipei, Taiwan) using the Hybrite system (Hibridizer, Dako) at $75^{\circ} \mathrm{C}$ for $5 \mathrm{~min}$ for codenaturation and at $37^{\circ} \mathrm{C}$ overnight for hybridization. Posthybridization stringency wash was carried on in $2 \times \mathrm{SSC} / 0.3 \%$ NP-40 at $73{ }^{\circ} \mathrm{C}$ for 2 min. Finally, slides were mounted with DAPI/antifade (Vector Laboratories, Burlingame, CA, USA) and examined with the epifluorescent microscope (Nikon, Eclipse 90i). FISH images were captured at $\times 100$ magnification and elaborated using the Genikon software (Nikon Instruments S.p.A., Italy).

The BAP1/CEN3q probe labels the chromosome 3 centromere green $(\mathrm{G})$ and the $B A P 1$ gene red $(\mathrm{R})$. In normal interphase cells, two green and two red signals $(2 \mathrm{G}-2 \mathrm{R})$ were clearly detectable. Based on the evaluation of 60 normal nuclei in each 6 normal samples, cutoff values for gene anomalies were defined as follows: (1) $20 \%$ for homozygous deletion (at least one green without red signals, $1 / 2 \mathrm{G}-0 \mathrm{R}$ or $>2 \mathrm{G}-0 \mathrm{R}$ ), (2) $29 \%$ for heterozygous deletion (two green with a single red signal, $2 \mathrm{G}-1 \mathrm{R}$, or green more numerous than red signals, $G>R$ ), and (3) $43 \%$ for chromosome 3 monosomy (a single green and red signal, 1G-1R).

Sensitivity and specificity, as well as diagnostic predictive values, were calculated using the online MedCalc statistical software (http://www.medcalc. org/calc/diagnostic_test.php); statistical analysis of mesothelioma incidence in reactive mesothelial proliferations in relation to BAP1 expression was performed using the two-tailed Fisher's exact test.

\section{Results}

\section{Normal Mesothelium and Benign Mesothelial Tumors Regularly Express BAP1 Protein}

In all control cases the flat monolayer surface mesothelium showed moderate to intense nuclear BAP1 expression. Similarly, BAP1 signal was easily detectable in all benign mesothelial tumors, independently from subtype and location (Figure 1). 


\section{BAP1 Loss in Reactive Mesothelial Proliferations Is Predictive of Malignancy}

In all, 36 cases of reactive mesothelial proliferations (25/27 simple and 11/15 atypical) showed BAP1 nuclear expression, whereas $2 / 27$ simple reactive mesothelial proliferations and 4/15 cases of atypical reactive mesothelial proliferation were BAP1 negative. All 6 (100\%) BAP1-negative reactive mesothelial proliferation cases were diagnosed having BAP1-negative mesothelioma within a time period between 2 and 104 weeks, whereas only 3/36 (8\%) cases of BAP1positive reactive mesothelial proliferation (1 simple and 2 atypical) had mesothelioma diagnosed within a time period between 3 and 56 weeks (Figure 2).

The incidence of mesothelioma in BAP1+ and BAP1 - reactive mesothelial proliferation cases was significantly different $(8 \%$ vS $100 \%$, respectively; Fisher's exact test: $P<0.0001)$; considering all reactive mesothelial proliferation excluding the 5 cases associated with pleural metastases (cases 22-26; Table 2) the lack of BAP1 expression had 100\% (95\% confidence interval: 54-100\%) positive predictive value and 90\% (95\% confidence interval: 74-98\%) negative predictive value for mesothelioma development, respectively.

\section{BAP1 Expression Is Frequently Lost in Malignant Mesothelioma, Especially in the Epithelioid Subtype}

Loss of BAP1 was observed in 139 of the 212 mesothelioma cases $(66 \%)$, particularly in the epithelioid $(128 / 184 ; 70 \%)$ and the biphasic subtypes (9/15; $60 \%$ ) (Figure 3a-d), whereas it was infrequent in the sarcomatoid and desmoplastic variants $(2 / 13 ; 15 \%)$. BAP1 protein loss was consistently observed in tumor cells in all cases except for two epithelioid mesotheliomas that showed tumor heterogeneity for the marker (Figure 3e and f). Interestingly, some invasive mesothelioma cases were associated with a surface mesothelium layer showing expression of BAP1 similar to that of the underlying invasive component, independently from its morphological growth pattern (single flat layer versus papillary) and the degree of cell atypia. On occasion, in BAP1negative cases, focal areas of surface mesothelium with preserved BAP1 expression were detected.

In five additional cases, extensive sampling from wide surgical resection of deeply invasive mesothelioma included tissue blocks defined as atypical reactive mesothelial proliferation as no invasion was detectable in the underlying stroma. In four of them, both the atypical reactive mesothelial proliferation and the invasive mesothelioma lacked BAP1, whereas the fifth case represented one of the mesotheliomas containing both BAP1+ and BAP1 tumoral cells and such heterogeneous neoplastic population was also clearly noticeable in the atypical reactive mesothelial proliferation areas.

Comparing the results of BAP1 expression in benign mesothelial lesions and mesothelioma, the sensitivity and specificity of BAP1 loss for diagnosing mesothelioma was 66\% (95\% confidence interval: $59-72 \%$ ) and $100 \%$, respectively; sensitivity increased to $69 \% \quad(95 \%$ confidence interval: $62-75 \%$ ) if only cases of epithelioid and biphasic mesotheliomas were considered.

\section{BAP1 Expression on Cytological and Cell-Block Samples}

Immunostain on cytological and cell-block samples was easily evaluable similar to tissue sections (Figure 4). In 15 cytological samples from obvious inflammatory pleural effusions and in 2 cases containing lung adenocarcinoma tumor cells, mesothelial cells regularly expressed BAP1. In 29 out of 45 cases of mesothelioma (64\%), BAP1 stain resulted negative in atypical mesothelial nuclei; one of these cases contained a mixed BAP1+ and BAP1 - tumor cell population according to the finding of BAP1 heterogeneity on the corresponding biopsy. In a further case, a BAP1 - cytological sample belonged to a patient on whom a histological diagnosis of BAP1+ mesothelioma was done 2 years before. Six out of 8 samples containing atypical mesothelial cells of unknown significance were BAP1 negative and all of them had a previous, concomitant, or subsequent biopsy showing BAP1 - mesothelioma. In the remaining two cases, mesothelial cells were BAP1 positive: one patient had BAP1+ mesothelioma and the other a non-Hodgkin's lymphoma involving the pleura.

\section{BAP1 Is Expressed in the Vast Majority of Lung and Ovarian Carcinomas}

In order to evaluate whether BAP1 might also be useful in the distinction between malignant mesothelioma and potential mimickers involving the pleura and peritoneum, a large cohort of tumor samples from lung and ovary carcinomas were analyzed. With the exception of one acinar and one solid lung adenocarcinomas that were totally BAP1 negative, all other cases strongly expressed BAP1 (Table 4 and Supplementary Figure 1). Interestingly, a minority of cases contained a BAP1-negative component associated with the predominant BAP1-positive one (Supplementary Figure 1). All eight samples of epithelioid hemangioendothelioma of the lung resulted intensely positive for BAP1 (Supplementary Figure 1).

\section{BAP1 Loss in Mesothelioma Is Frequently Sustained by Homozygous Deletion of BAP1 Gene by FISH}

All six control samples containing normal mesothelium showed unaltered $B A P 1$ gene pattern on FISH $(2 \mathrm{G}-2 \mathrm{R})$. In 36 of 41 (88\%) BAP1-negative mesothelioma cases, at least one abnormality at the $B A P 1$ locus was observed. As defined by the established 

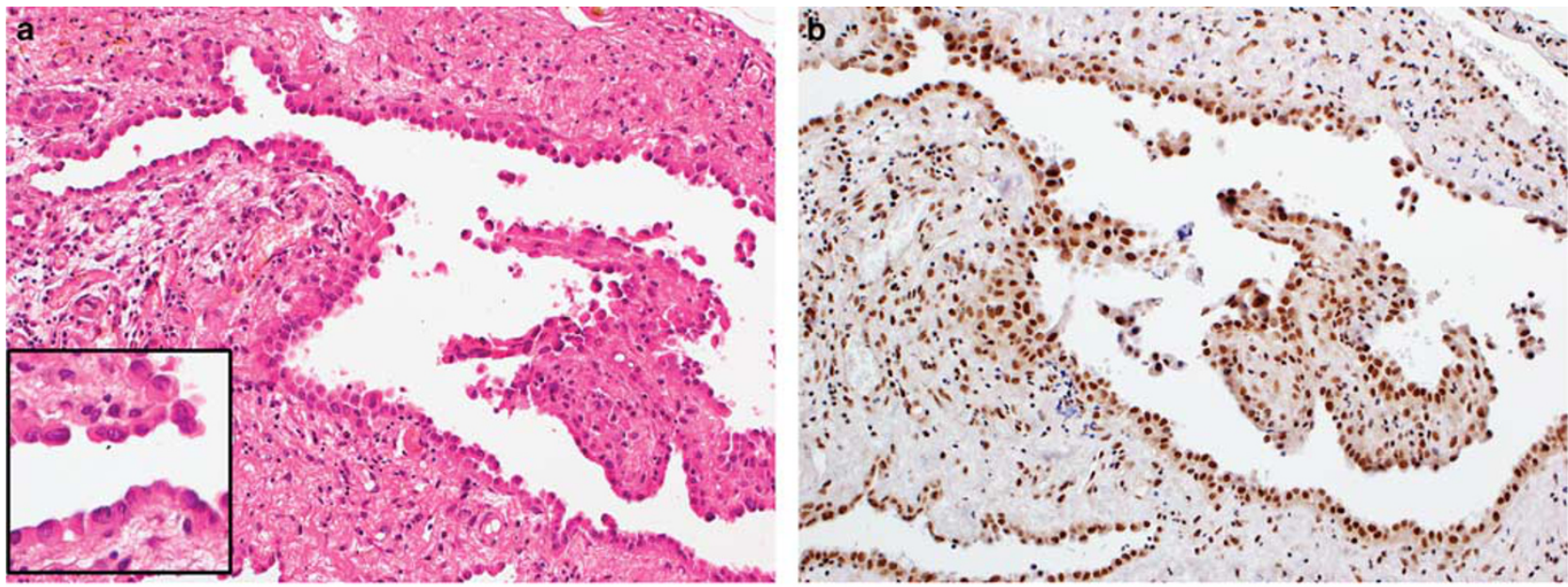

C

\section{d}
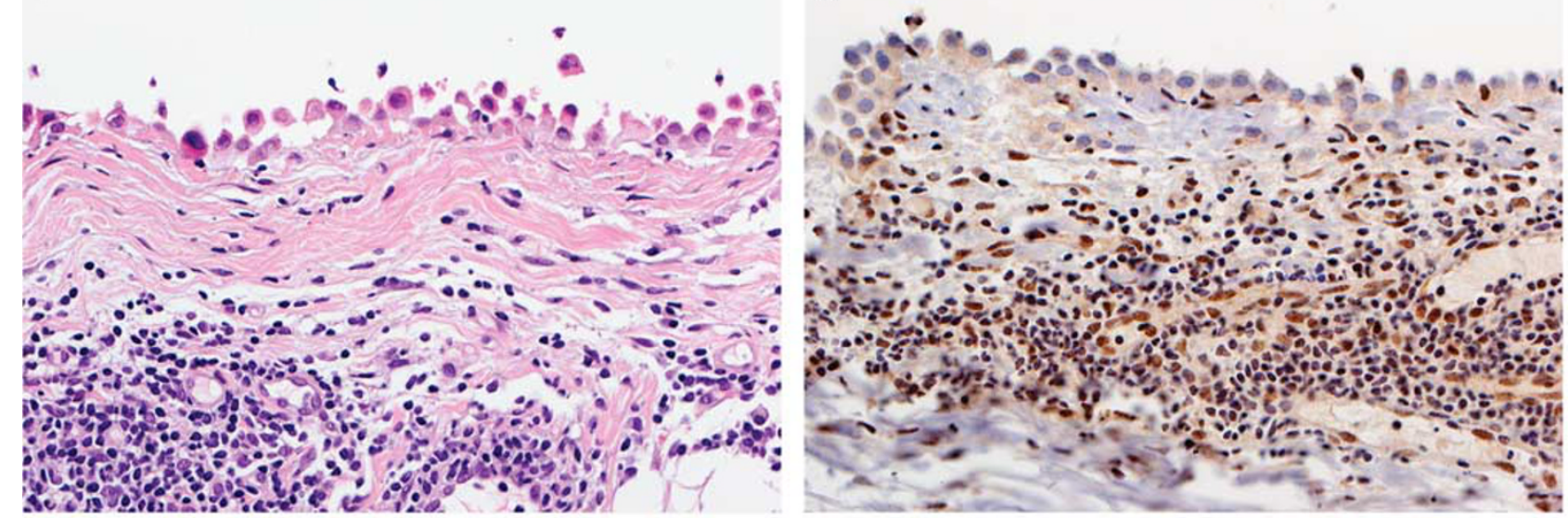

e

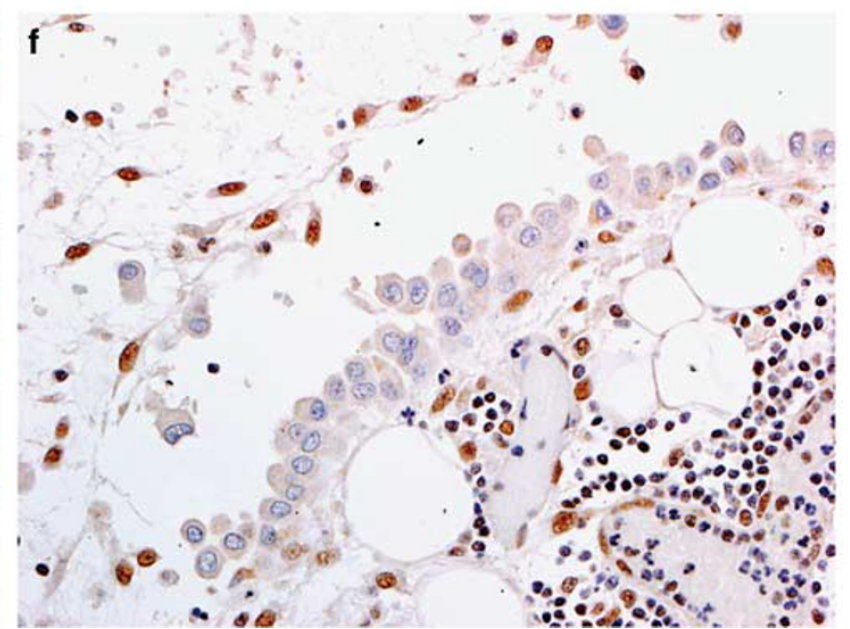

Figure 2 BAP1 immunostain in cases of noninvasive mesothelial proliferations. (a and b) Case 28 in Table 2. Hematoxylin and eosin shows the irregular mesothelial proliferation with papillae (a) and cytological atypical features (inset); BAP1 is strongly reactive in mesothelial and stromal-inflammatory cells. (c-f) Three different cases of mesothelial proliferation showing BAP1 negativity that were associated with mesothelioma (c and $\mathbf{d}$ : case 19, e: case 18; and f: case 40, all from Table 2).

cutoff values, homozygous deletion was detected in 31 cases $(76 \% ; 1 / 2 \mathrm{G}-0 \mathrm{R}$ or $>2 \mathrm{G}-0 \mathrm{R}$; Figure $5 \mathrm{~b}) ; 6$ of them also contained cells with heterozygous deletion. Heterozygous-only deletion was found in one case $(2 G-1 R$ or $G>R)$, whereas three cases showed chromosome 3 monosomy (1G-1R). Finally, one case showed unexpected chromosome 3 polysomy.

Remarkably, in one mesothelioma case, tumor heterogeneity at the protein level was supported by heterogeneous deletion of the $B A P 1$ locus in 

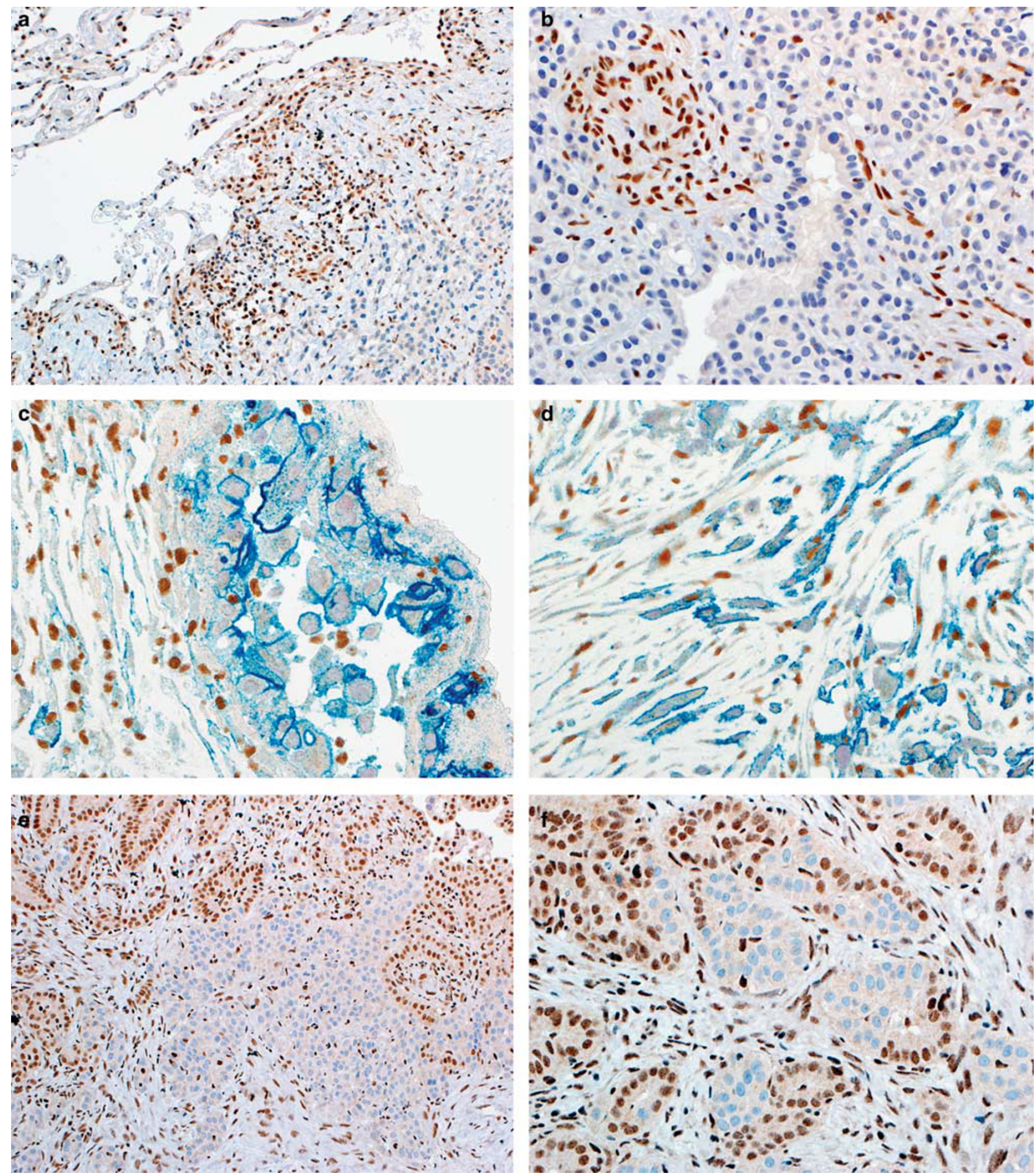

Figure 3 (a-d) Examples of three BAP1-negative malignant epithelioid and biphasic mesotheliomas. (a) The BAP1-positive lung parenchyma (upper left) infiltrated by the mesothelioma (lower right); (b) BAP1 is expressed by inflammatory cells and vascular endothelium within the tumor. (c and d) A case of biphasic mesothelioma double stained for BAP1 (brown) and epithelial membrane antigen (blue), the latter being helpful to identify the BAP1-negative spindle cells in the sarcomatoid areas. (e and f) The only two cases of epithelioid mesothelioma containing distinct tumor populations regarding BAP1 expression.

mesothelioma cells. Eight of 10 BAP1-positive mesotheliomas showed no BAP1 anomalies (Figure 5a). One homozygous deletion and one gene amplification pattern were detected in the remaining two cases, respectively.

\section{Discussion}

By analyzing a large cohort of clinical samples, this study establishes that BAP1 expression by immunohistochemistry represents a biomarker of excellent 
clinical utility for the diagnosis of malignant mesothelioma. Although expressed in all benign mesothelial lesions, BAP1 protein was lost in a large proportion of mesotheliomas, especially with epithelioid $(128 / 184,70 \%)$ and biphasic $(9 / 15,60 \%)$ features. BAP1 loss was also seen in sarcomatoid and
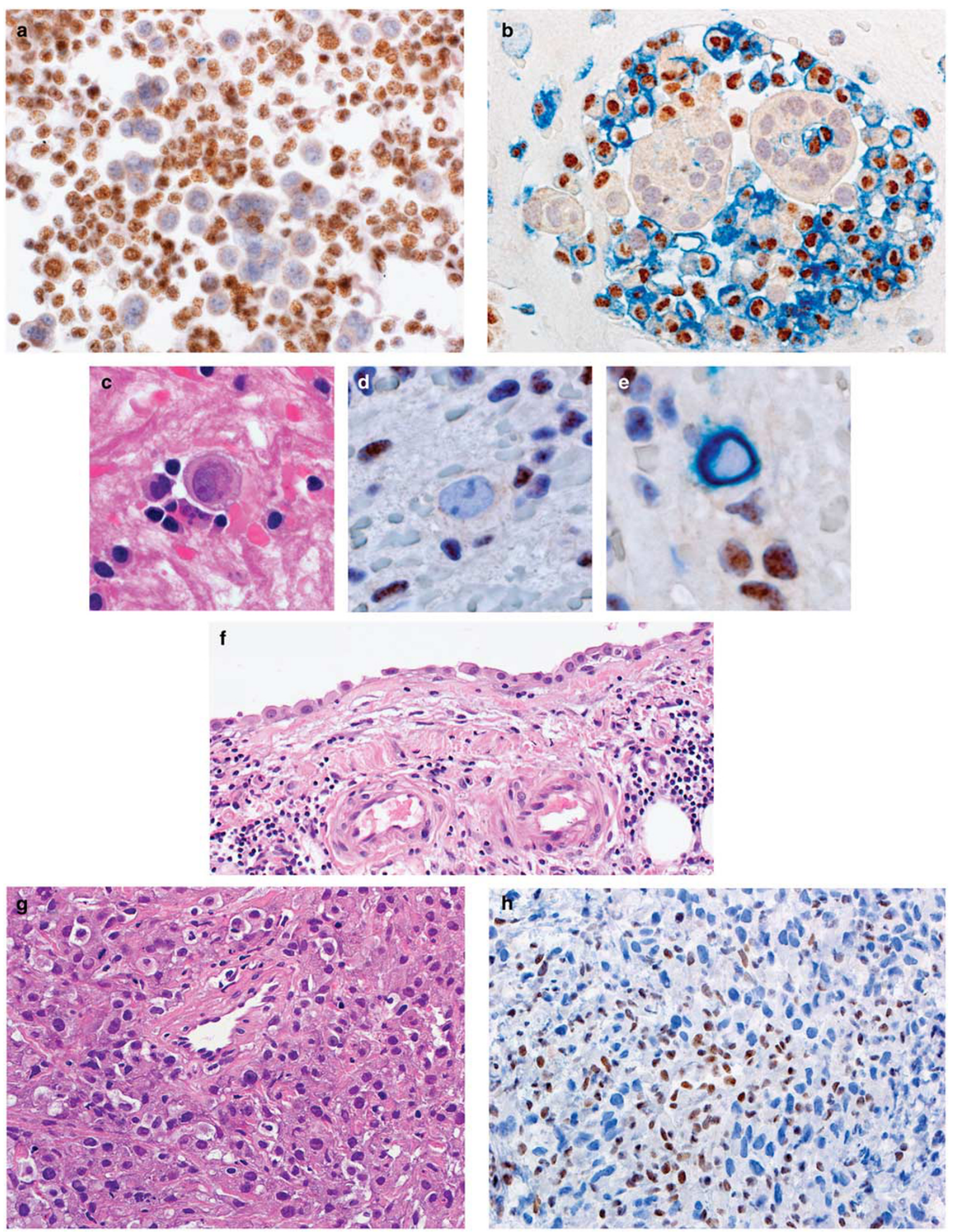
desmoplastic mesothelioma, although with lower frequency $(2 / 13,15 \%)$. Remarkably, BAP1 protein loss was paralleled by homozygous deletion of the
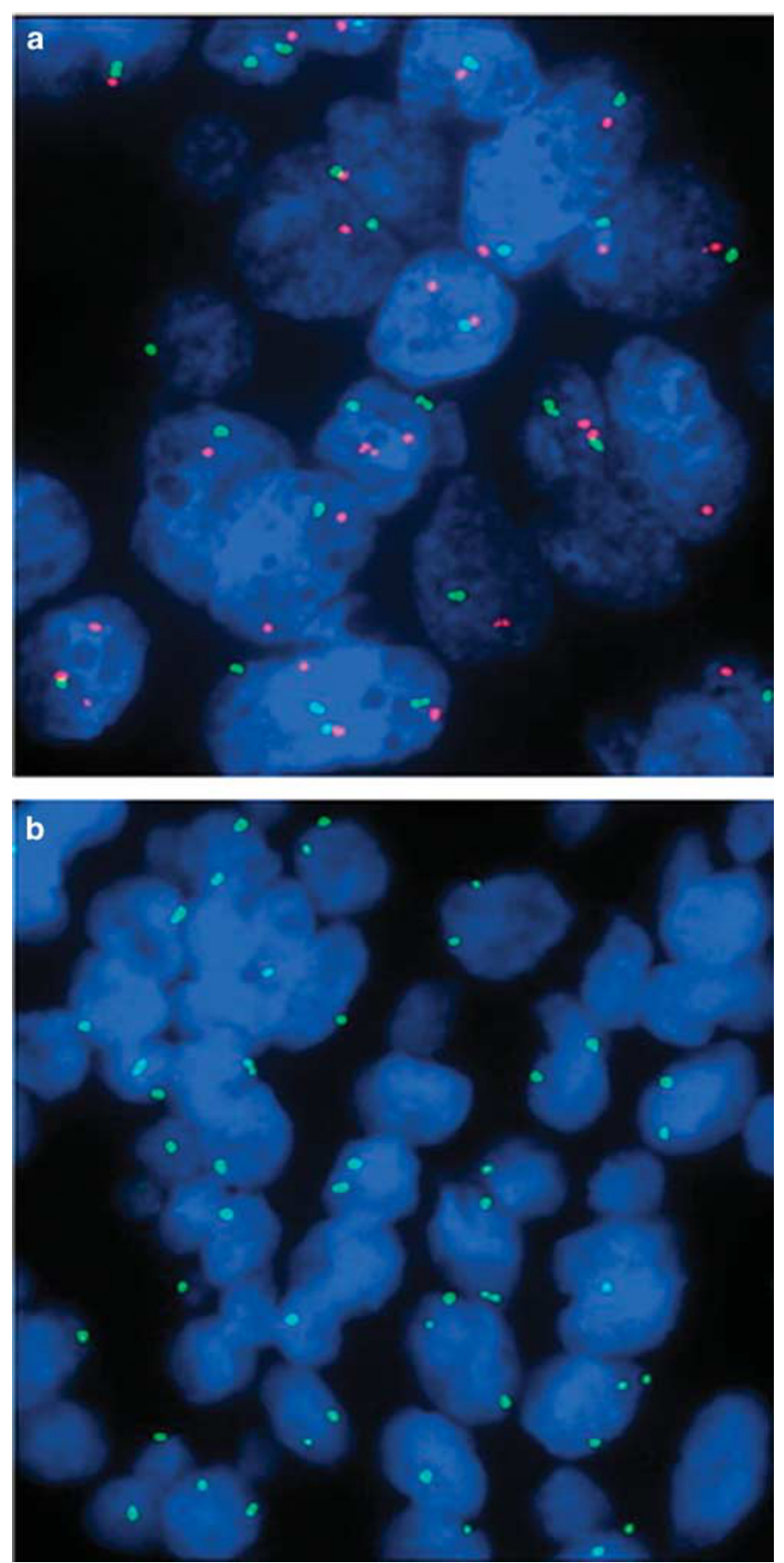

Figure 5 Fluorescence in situ hybridization using the BAP1/ CEN3q probe in a case of BAP1-positive mesothelioma that shows normal copy numbers (a) and in a case of BAP1-negative mesothelioma with homozygous deletion of BAP1 (b).
$B A P 1$ locus in the vast majority of BAP1-negative tumors $(31 / 41,76 \%)$. Our results show the high specificity $(100 \%)$ of BAP1 loss for mesothelioma diagnosis, in keeping with data recently obtained on a small series of tissue microarray mesothelial lesions; ${ }^{39}$ in contrast with the latter study, however, sensitivity was much higher $(66 \%$ versus $27 \%)$, probably because of the higher number of epithelioid/biphasic mesothelioma cases included in the present study.

The use of BAP1 immunostain can be particularly useful in the differential diagnosis between mesothelioma and reactive mesothelial proliferations that can be challenging in several instances ${ }^{9-11,61}$ and especially on small tissue samples where stromal invasion cannot be properly evaluated. In this differential scenario, the role of immunohistochemistry is very controversial, as the results obtained using several markers (e.g., desmin, epithelial membrane antigen, p53, IMP3, GLUT-1, CD146, CD147, p16) were poorly reproducible among studies, with marked variability in sensitivity and specificity. ${ }^{13-38}$ This lack of reproducibility might depend on preanalytical issues ${ }^{62}$ or, alternatively, on data interpretation (eg, definition of the biomarker cutoff values). In contrast, the evaluation of BAP1 immunostain is straightforward and protein loss or retention is easily recognizable, therefore requiring no threshold values. BAP1-negative tumor cells were also easily recognizable in mesothelioma cases showing heterogeneity. Notably, in one of the cases, FISH analysis confirmed heterogeneity at the genomic level.

BAP1 stain in reactive mesothelial proliferations was of great support in the identification of malignancy, as five cases originally defined as simple or atypical reactive mesothelial proliferation and lacking protein expression were diagnosed having mesothelioma within a time period ranging from 2 to 104 weeks. An additional fifth case classified as atypical reactive mesothelial proliferation of the peritoneum was from a patient who died 4 years later with multiple abdominal metastases; unfortunately, no further biopsies were performed in this case. Overall, BAP1 negativity in cases of reactive mesothelial proliferation had a $100 \%$ positive predictive value for mesothelioma development, whereas BAP1 positivity had a negative predictive value of $90 \%$.

Interestingly, the reactivity of BAP1 (including BAP1 loss) was highly concordant between the invasive component and the surface mesothelial layer, independently from its morphological features

Figure 4 BAP1 immunostain on cytological (a) and cell-block (b) samples from two cases of epithelioid mesothelioma showing BAP1negative malignant cells surrounded by numerous BAP1-positive inflammatory cells. Double stain for BAP1 (brown) and CD11c (blue) reveals the histiocytic nature of the BAP1-positive cells embedding the tumor papillae (b). (c-h) Shown is a patient (no. 42 in Table 2) who showed pleural effusion containing rare atypical cells (c) that resulted negative for BAP1 (d, single immunostain for BAP1; e, double immunostain for BAP1 and cytokeratin 5/6, respectively brown and blue); pleural biopsy was unremarkable (f); 11 months later, frank invasive BAP1-negative mesothelioma was diagnosed ( $\mathbf{g}$ and $\mathbf{h})$. 
and degree of atypia. This indicates that, in a fraction of mesotheliomas, loss of BAP1 protein might represent an early and irreversible event anticipating full mesothelial transformation. With this in mind, biopsies including only BAP1-negative surface mesothelium should lead to immediate reevaluation to exclude invasive mesothelioma. A similar conclusion was made by Hwang et $a l^{63}$ who applied FISH for the CDKN2A gene in 18 mesotheliomas and found homozygous deletion in 6/18 cases in both invasive tumor and the corresponding surface mesothelial proliferation.

In addition to its relevant role in distinguishing mesothelioma from reactive mesothelial proliferations, BAP1 stain also showed utility in the differential of mesothelioma from most common pleural and peritoneal mimickers, such as lung and ovary carcinomas, with specificity and sensitivity of 99/70\% and 100/70\%, respectively.

Malignant mesothelioma often presents with recurrent serous effusions and cytology of the pleural fluid represents the initial diagnostic procedure. Unfortunately, the diagnostic sensitivity is extremely variable with a high rate of false-negative cases, the latter finding partially explained by the broad morphologic overlap between reactive and malignant mesothelial cells. ${ }^{64,65}$ Accordingly, the International Mesothelioma Interest Group established that effusion cytology has limited usefulness for a definitive diagnosis of mesothelioma. ${ }^{65}$ Immunohistochemical markers used on histological samples to differentiate between benign and malignant mesothelial proliferation have also been used in cytology with similar unsatisfactory results. ${ }^{28-36}$ The present study shows that the BAP1 profile of mesothelial cells is also easily identifiable on effusions and cell blocks. Benign mesothelial cells were invariably positive for BAP1, whereas $64 \%$ of mesotheliomas showed loss of protein; in equivocal cases by morphology, BAP1 negativity on mesothelial cells had a $100 \%$ positive predictive value for the diagnosis of mesothelioma: all six samples containing mesothelial cells negative for BAP1 were associated with a histological diagnosis of BAP1-negative mesothelioma.

$B A P 1$ gene loss of function has been previously detected in cases of sporadic mesothelioma and related to different and sometimes coexisting mechanisms, including homozygous/heterozygous deletions or sequence mutations. ${ }^{54,56,58,66}$ The possibility of posttranslational mechanism has also been considered, as loss of protein has been occasionally associated with preserved BAP1 transcript. ${ }^{54}$ In this study FISH analysis of BAP1 gene showed that 32 out of 41 BAP1-negative mesotheliomas revealed biallelic $(31 / 41,76 \%)$ or monoallelic $(1 / 41,2 \%)$ deletion of the BAP1 locus; in other studies performed on mesothelioma cohorts not selected on the basis of BAP1 expression, gene deletions were detected with lower frequency. ${ }^{54,56,66}$ Interestingly, $B A P 1$ homozygous deletion was also identified in
1 out of 10 cases of mesothelioma expressing BAP1 protein; it is conceivable to retain that in this single case the gene region transcribing the epitope recognized by anti-BAP1 antibody is uncovered by the $B A P 1$ probe. Taken together, these data suggest that $B A P 1$ FISH analysis can support immunohistochemistry in confirming the diagnosis of mesothelioma.

A striking difference in the percentage of mesothelioma cases showing BAP1 loss was found between epithelioid/biphasic and sarcomatoid/desmoplastic mesothelioma (69\% versus $15 \%$ ). These data are in keeping with those reported by Yoshikawa et al, ${ }^{56}$ whereas Bott et al ${ }^{54}$ did not find correlation between gene anomalies and histologic mesothelioma variants. It is known that epithelioid and sarcomatoid mesotheliomas show different antigen expression, with many mesothelial markers being frequently negative in sarcomatoid subtype. ${ }^{67-73}$ A recent gene expression profile analysis applied to a large series of pleural mesothelioma cell lines and tissue samples identified two mesothelioma subgroups. Although sarcomatoid and desmoplastic mesotheliomas belonged to a single group associated with poorer prognosis, epithelioid mesotheliomas were either included in the sarcomatoid/desmoplastic group or fell in a distinct subgroup with a better prognosis. Interestingly, in this study mutation analysis of $B A P 1, C D K N 2 A, C D K N 2 B, N F 2$, and TP53 was also performed and showed that the subgroup with better prognosis exhibited more frequent $B A P 1$ genetic variants. ${ }^{74}$ This observation is in keeping with the data obtained by Arzt et al ${ }^{57}$ who found that lack of BAP1 protein expression in mesothelioma is associated with better survival.

The role of BAP1 mutations during mesothelial transformation is poorly understood. In contrast to sporadic or familiar atypical Spitz tumors where $B A P 1$ mutations are not sufficient to induce malignant transformation, ${ }^{52}$ in mesothelial cells their occurrence is invariably associated with malignancy. A recent study in mice showed that the heterozygous deletion of BAP1 increased the susceptibility to mesothelioma induced by chronic exposure to asbestos; interestingly, transformed mesothelial cells acquired a second hit and showed biallelic loss of $B A P 1$ gene. $^{75} B A P 1$ haploinsufficiency, however, is not sufficient to promote spontaneous tumorigenesis in the host, as no mesotheliomas or other malignancies were observed in unexposed mice during 87 weeks of surveillance.

In conclusion, this study shows that BAP1 protein is frequently lost in malignant mesothelioma, especially of epithelioid/biphasic subtype (69\%). This marker has an absolute specificity $(100 \%)$ in the distinction between benign and malignant mesothelial proliferations, whereas sensitivity is lower. Nevertheless, in cases with uncertain diagnosis the identification of loss of BAP1 protein in mesothelial cells should prompt to immediately reevaluate the patient with additional biopsies or close follow-up. BAP1 loss might be useful in 
mapping tumor extent and planning surgical resection, especially in peritoneal mesothelioma where prognosis may depend on surgical radicality. ${ }^{76}$ Finally, despite the fact that loss of protein likely depends more commonly on somatic events involving the BAP1 gene, the identification of mesothelioma with BAP1-negative phenotype might guide to perform $B A P 1$ germline testing in family members.

\section{Acknowledgments}

This study was partially supported by MIUR (to FF) and Fondazione Beretta (to MB). We thank Dr Gino Pietro Barbieri (Servizio Prevenzione e Sicurezza negli Ambienti di Lavoro, ASL Brescia) for his support in follow-up analysis and enquiry of patients' follow-up in Brescia and National Mesothelioma Registry. We are also grateful to Dr Raffaella Marucci for providing cytological samples. This study is dedicated to the memory of Tiziana Serelli Facchetti.

\section{Disclosure/conflict of interest}

The authors declare no conflict of interest.

\section{References}

1 Price B, Ware A. Mesothelioma trends in the United States: an update based on Surveillance, Epidemiology, and End Results Program data for 1973 through 2003. Am J Epidemiol 2004;159:107-112.

2 Yang H, Testa JR, Carbone M. Mesothelioma epidemiology, carcinogenesis, and pathogenesis. Curr Treat Options Oncol 2008;9:147-157.

3 Surveillance, Epidemiology, and End Results Program. In: NCI (http://seer.cancer.gov/) 2015.

4 Marinaccio A, Binazzi A, Branchi C et al. Registro Nazionale dei Mesoteliomi. Quarto Rapporto. Istituto Nazionale per l'Assicurazione contro gli Infortuni sul Lavoro: Roma2012.

5 Marinaccio A, Binazzi A, Marzio DD et al. Pleural malignant mesothelioma epidemic: incidence, modalities of asbestos exposure and occupations involved from the Italian National Register. Int J Cancer 2012;130:2146-2154.

6 Peto J, Decarli A, La Vecchia C et al. The European mesothelioma epidemic. Br J Cancer 1999;79:666-672.

7 Marinaccio A, Montanaro F, Mastrantonio $\mathrm{M}$ et al. Predictions of mortality from pleural mesothelioma in Italy: a model based on asbestos consumption figures supports results from age-period-cohort models. Int J Cancer 2005;115:142-147.

8 Ordonez NG. Immunohistochemical diagnosis of epithelioid mesotheliomas: a critical review of old markers, new markers. Hum Pathol 2002;33:953-967.

9 Ordonez NG. Application of immunohistochemistry in the diagnosis of epithelioid mesothelioma: a review and update. Hum Pathol 2013;44:1-19.

10 Churg A, Cagle P, Roggli VL. Separation of benign and malignant mesothelial proliferations. In: Silverberg SG (ed). Tumors of the Serosal Membranes, 4th edn. Vol. 3.
The American Registry of Pathology: Washington, DC, 2006, pp 83-101.

11 Churg A, Galateau-Salle F. The separation of benign and malignant mesothelial proliferations. Arch Pathol Lab Med 2012;136:1217-1226.

12 Henderson DW, Reid G, Kao SC et al. Challenges and controversies in the diagnosis of mesothelioma: Part 1. Cytology-only diagnosis, biopsies, immunohistochemistry, discrimination between mesothelioma and reactive mesothelial hyperplasia, and biomarkers. J Clin Pathol 2013;66:847-853.

13 Cury PM, Butcher DN, Corrin B et al. The use of histological and immunohistochemical markers to distinguish pleural malignant mesothelioma and in situ mesothelioma from reactive mesothelial hyperplasia and reactive pleural fibrosis. J Pathol 1999;189: 251-257.

14 Roberts F, Harper CM, Downie I et al. Immunohistochemical analysis still has a limited role in the diagnosis of malignant mesothelioma. A study of thirteen antibodies. Am J Clin Pathol 2001;116:253-262.

15 Attanoos RL, Griffin A, Gibbs AR. The use of immunohistochemistry in distinguishing reactive from neoplastic mesothelium. A novel use for desmin and comparative evaluation with epithelial membrane antigen, p53, platelet-derived growth factor-receptor, P-glycoprotein and Bcl-2. Histopathology 2003;43:231-238.

16 Minato H, Kurose N, Fukushima $\mathrm{M}$ et al. Comparative immunohistochemical analysis of IMP3, GLUT1, EMA, CD146, and desmin for distinguishing malignant mesothelioma from reactive mesothelial cells. Am J Clin Pathol 2014;141:85-93.

17 Ramael M, Lemmens G, Eerdekens C et al. Immunoreactivity for p53 protein in malignant mesothelioma and non-neoplastic mesothelium. J Pathol 1992;168: 371-375.

18 Mayall FG, Goddard H, Gibbs AR. p53 immunostaining in the distinction between benign and malignant mesothelial proliferations using formalin-fixed paraffin sections. J Pathol 1992;168:377-381.

19 Cagle PT, Brown RW, Lebovitz RM. p53 immunostaining in the differentiation of reactive processes from malignancy in pleural biopsy specimens. Hum Pathol 1994;25:443-448.

20 Shi M, Fraire AE, Chu P et al. Oncofetal protein IMP3, a new diagnostic biomarker to distinguish malignant mesothelioma from reactive mesothelial proliferation. Am J Surg Pathol 2011;35:878-882.

21 Lee AF, Gown AM, Churg A. IMP3 and GLUT-1 immunohistochemistry for distinguishing benign from malignant mesothelial proliferations. Am J Surg Pathol 2013;37:421-426.

22 Kato Y, Tsuta K, Seki K et al. Immunohistochemical detection of GLUT-1 can discriminate between reactive mesothelium and malignant mesothelioma. Mod Pathol 2007;20:215-220.

23 Monaco SE, Shuai Y, Bansal M et al. The diagnostic utility of p16 FISH and GLUT-1 immunohistochemical analysis in mesothelial proliferations. Am J Clin Pathol 2011;135:619-627.

24 Lagana SM, Taub RN, Borczuk AC. Utility of glucose transporter 1 in the distinction of benign and malignant thoracic and abdominal mesothelial lesions. Arch Pathol Lab Med 2012;136:804-809.

25 Mogi A, Koga K, Aoki M et al. Expression and role of GLUT-1, MCT-1, and MCT-4 in malignant pleural mesothelioma. Virchows Arch 2013;462:83-93. 
26 Husain AN, Mirza MK, Gibbs A et al. How useful is GLUT-1 in differentiating mesothelial hyperplasia and fibrosing pleuritis from epithelioid and sarcomatoid mesotheliomas? An international collaborative study. Lung Cancer 2014;83:324-328.

27 Pinheiro C, Longatto-Filho A, Soares TR et al. CD147 immunohistochemistry discriminates between reactive mesothelial cells and malignant mesothelioma. Diagn Cytopathol 2012;40:478-483.

28 Dejmek A, Hjerpe A. Reactivity of six antibodies in effusions of mesothelioma, adenocarcinoma and mesotheliosis: stepwise logistic regression analysis. Cytopathology 2000;11:8-17.

29 Aerts JG, Delahaye M, van der Kwast TH et al. The high post-test probability of a cytological examination renders further investigations to establish a diagnosis of epithelial malignant pleural mesothelioma redundant. Diagn Cytopathol 2006;34:523-527.

30 Shen J, Pinkus GS, Deshpande V et al. Usefulness of EMA, GLUT-1, and XIAP for the cytologic diagnosis of malignant mesothelioma in body cavity fluids. Am J Clin Pathol 2009;131:516-523.

31 Hasteh F, Lin GY, Weidner $\mathrm{N}$ et al. The use of immunohistochemistry to distinguish reactive mesothelial cells from malignant mesothelioma in cytologic effusions. Cancer Cytopathol 2010;118:90-96.

32 Sato A, Torii I, Okamura Y et al. Immunocytochemistry of CD146 is useful to discriminate between malignant pleural mesothelioma and reactive mesothelium. Mod Pathol 2010;23:1458-1466.

33 Ikeda K, Tate G, Suzuki T et al. IMP3/L523S, a novel immunocytochemical marker that distinguishes benign and malignant cells: the expression profiles of IMP3/ L523S in effusion cytology. Hum Pathol 2010;41:745-750.

34 Ikeda K, Tate G, Suzuki T et al. Diagnostic usefulness of EMA, IMP3, and GLUT-1 for the immunocytochemical distinction of malignant cells from reactive mesothelial cells in effusion cytology using cytospin preparations. Diagn Cytopathol 2011;39:395-401.

35 Su XY, Li GD, Liu WP et al. Cytological differential diagnosis among adenocarcinoma, epithelial mesothelioma, and reactive mesothelial cells in serous effusions by immunocytochemistry. Diagn Cytopathol 2011;39:900-908.

36 Mayall F, Heryet A, Manga D et al. p53 immunostaining is a highly specific and moderately sensitive marker of malignancy in serous fluid cytology. Cytopathology 1997;8:9-12.

37 Chiosea S, Krasinskas A, Cagle PT et al. Diagnostic importance of 9p21 homozygous deletion in malignant mesotheliomas. Mod Pathol 2008;21:742-747.

38 Takeda M, Kasai T, Enomoto Y et al. 9p21 deletion in the diagnosis of malignant mesothelioma, using fluorescence in situ hybridization analysis. Pathol Int 2010;60:395-399.

39 Sheffield BS, Hwang HC, Lee AF et al. BAP1 immunohistochemistry and p16 FISH to separate benign from malignant mesothelial proliferations. Am J Surg Pathol; advance online publication, 28 January 2015 (e-pub ahead of print).

40 Carbone M, Ferris LK, Baumann F et al. BAP1 cancer syndrome: malignant mesothelioma, uveal and cutaneous melanoma, and MBAITs. J Transl Med 2012;10:179.

41 Jensen DE, Proctor M, Marquis ST et al. BAP1: a novel ubiquitin hydrolase which binds to the BRCA1 RING finger and enhances BRCA1-mediated cell growth suppression. Oncogene 1998;16:1097-1112.
42 Ventii KH, Devi NS, Friedrich KL et al. BRCA1associated protein-1 is a tumor suppressor that requires deubiquitinating activity and nuclear localization. Cancer Res 2008;68:6953-6962.

43 Nishikawa $\mathrm{H}, \mathrm{Wu}$ W, Koike A et al. BRCA1-associated protein 1 interferes with BRCA1/BARD1 RING heterodimer activity. Cancer Res 2009;69:111-119.

44 Shen SX, Weaver Z, Xu X et al. A targeted disruption of the murine Brca1 gene causes gamma-irradiation hypersensitivity and genetic instability. Oncogene 1998;17:3115-3124.

$45 \mathrm{Yu}$ H, Pak H, Hammond-Martel I et al. Tumor suppressor and deubiquitinase BAP1 promotes DNA doublestrand break repair. Proc Natl Acad Sci USA 2014;111: 285-290.

46 Ismail IH, Davidson R, Gagne JP et al. Germline mutations in BAP1 impair its function in DNA double-strand break repair. Cancer Res 2014;74:4282-4294.

47 Machida YJ, Machida Y, Vashisht AA et al. The deubiquitinating enzyme BAP1 regulates cell growth via interaction with HCF-1. J Biol Chem 2009;284: 34179-34188.

48 Yu H, Mashtalir N, Daou S et al. The ubiquitin carboxyl hydrolase BAP1 forms a ternary complex with YY1 and HCF-1 and is a critical regulator of gene expression. Mol Cell Biol 2010;30:5071-5085.

49 Carbone M, Yang H, Pass HI et al. BAP1 and cancer. Nat Rev Cancer 2013;13:153-159.

50 Harbour JW, Onken MD, Roberson ED et al. Frequent mutation of BAP1 in metastasizing uveal melanomas. Science 2010;330:1410-1413.

51 Joseph RW, Kapur P, Serie DJ et al. Loss of BAP1 protein expression is an independent marker of poor prognosis in patients with low-risk clear cell renal cell carcinoma. Cancer 2014;120:1059-1067.

52 Wiesner $\mathrm{T}$, Obenauf AC, Murali R et al. Germline mutations in BAP1 predispose to melanocytic tumors. Nat Genet 2011;43:1018-1021.

53 Wiesner T, Murali R, Fried I et al. A distinct subset of atypical Spitz tumors is characterized by BRAF mutation and loss of BAP1 expression. Am J Surg Pathol 2012;36:818-830.

54 Bott M, Brevet M, Taylor BS et al. The nuclear deubiquitinase BAP1 is commonly inactivated by somatic mutations and 3p21.1 losses in malignant pleural mesothelioma. Nat Genet 2011;43:668-672.

55 Yoshikawa Y, Sato A, Tsujimura T et al. Frequent deletion of 3p21.1 region carrying semaphorin 3G and aberrant expression of the genes participating in semaphorin signaling in the epithelioid type of malignant mesothelioma cells. Int J Oncol 2011;39: 1365-1374.

56 Yoshikawa Y, Sato A, Tsujimura $\mathrm{T}$ et al. Frequent inactivation of the BAP1 gene in epithelioid-type malignant mesothelioma. Cancer Sci 2012;103:868-874.

57 Arzt L, Quehenberger F, Halbwedl I et al. BAP1 protein is a progression factor in malignant pleural mesothelioma. Pathol Oncol Res 2013;20:145-151.

58 Nasu M, Emi M, Pastorino S et al. High incidence of somatic BAP1 alterations in sporadic malignant mesothelioma. J Thorac Oncol 2015;10:565-576.

59 Facchetti F, Lonardi S, Gentili F et al. Claudin 4 identifies a wide spectrum of epithelial neoplasms and represents a very useful marker for carcinoma versus mesothelioma diagnosis in pleural and peritoneal biopsies and effusions. Virchows Arch 2007;451: 669-680. 
60 Vermi W, Lonardi S, Morassi M et al. Cutaneous distribution of plasmacytoid dendritic cells in lupus erythematosus. Selective tropism at the site of epithelial apoptotic damage. Immunobiology 2009;214: 877-886.

61 Henderson DW, Reid G, Kao SC et al. Challenges and controversies in the diagnosis of malignant mesothelioma: Part 2. Malignant mesothelioma subtypes, pleural synovial sarcoma, molecular and prognostic aspects of mesothelioma, BAP1, aquaporin-1 and microRNA. J Clin Pathol 2013;66:854-861.

62 King JE, Thatcher N, Pickering CA et al. Sensitivity and specificity of immunohistochemical markers used in the diagnosis of epithelioid mesothelioma: a detailed systematic analysis using published data. Histopathology 2006;48:223-232.

63 Hwang H, Tse C, Rodriguez S et al. p16 FISH deletion in surface epithelial mesothelial proliferations is predictive of underlying invasive mesothelioma. Am J Surg Pathol 2014;38:681-688.

64 Churg A, Cagle P, Roggli VL. Cytology of the serosal surfaces. In: Silverberg SG (ed). Tumors of the Serosal Membranes, 4th edn. Vol. 3. The American Registry of Pathology: Washington: Washington, DC, 2006, pp 11-31.

65 Husain AN, Colby T, Ordonez N et al. Guidelines for pathologic diagnosis of malignant mesothelioma: 2012 update of the consensus statement from the International Mesothelioma Interest Group. Arch Pathol Lab Med 2013;137:647-667.

66 Guo G, Chmielecki J, Goparaju C et al. Whole-exome sequencing reveals frequent genetic alterations in BAP1, NF2, CDKN2A, and CUL1 in malignant pleural mesothelioma. Cancer Res 2015;75:264-269.

67 Attanoos RL, Dojcinov SD, Webb R et al. Anti-mesothelial markers in sarcomatoid mesothelioma and other spindle cell neoplasms. Histopathology 2000; 37:224-231.

68 Lucas DR, Pass HI, Madan SK et al. Sarcomatoid mesothelioma and its histological mimics: a comparative immunohistochemical study. Histopathology 2003;42:270-279.

69 Takeshima Y, Amatya VJ, Kushitani K et al. Value of immunohistochemistry in the differential diagnosis of pleural sarcomatoid mesothelioma from lung sarcomatoid carcinoma. Histopathology 2009;54:667-676.

70 Travis WD. Sarcomatoid neoplasms of the lung and pleura. Arch Pathol Lab Med 2010;134:1645-1658.

71 Klebe S, Brownlee NA, Mahar A et al. Sarcomatoid mesothelioma: a clinical-pathologic correlation of 326 cases. Mod Pathol 2010;23:470-479.

72 Sun X, Wei L, Liden J et al. Molecular characterization of tumour heterogeneity and malignant mesothelioma cell differentiation by gene profiling. J Pathol 2005;207: 91-101.

73 Roggli V, Churg A, Chirieac LR et al. Sarcomatoid, desmoplastic, and biphasic mesothelioma. In: Travis WD, Brambilla E, Burke AP, Marx A and Nicholson AG (eds). WHO Classification of Tumours of the Lung, Pleura, Thymus and Heart. IV edn. IARC Press: Lyon, 2015, pp 165-168.

74 de Reynies A, Jaurand MC, Renier A et al. Molecular classification of malignant pleural mesothelioma: identification of a poor prognosis subgroup linked to the epithelial-to-mesenchymal transition. Clin Cancer Res 2014;20:1323-1334.

$75 \mathrm{Xu}$ J, Kadariya Y, Cheung M et al. Germline mutation of bap1 accelerates development of asbestos-induced malignant mesothelioma. Cancer Res 2014;74:4388-4397.

76 Cao C, Yan TD, Deraco M et al. Importance of gender in diffuse malignant peritoneal mesothelioma. Ann Oncol 2012;23:1494-1498.

Supplementary Information accompanies the paper on Modern Pathology website (http://www.nature.com/ modpathol) 